\title{
Protective Effects of Adiponectin Against Diabetic Renal Injury in a Mouse Model of Diabetes
}

\author{
Jiacai Hu Junjun Dong Zhijie Yang Hao Wu Na Yang \\ Department of Traditional Chinese Medicine, Renmin Hospital of Wuhan University, Wuhan, Hubei, \\ China
}

\section{Key Words}

Type 2 diabetes • Adiponectin • Antioxidation • Insulin

\begin{abstract}
:
Background/Aims: Adiponectin (Apn) has shown anti-diabetic and anti-inflammatory potential. In the study, we studied and tested the protective effects of Apn against diabetic renal injury and the possible mechanism of these effects. Methods: After 1 week of adaptive feeding, 30 mice were randomly divided into 5 groups: the control group, the model group, the Apn (L) group, the Apn (M) group and the Apn $(\mathrm{H})$ group. All mice were marked and weighed. Following 4 weeks of a pro-diabetic high-fat diet, the model group and Apn groups were injected intraperitoneally with a high dose of STZ $(85 \mathrm{mg} / \mathrm{kg})$, while the normal control group was injected with sodium citrate. Fasting blood glucose was measured daily, starting 3 days after STZ injection. After confirming the success of the diabetic model by measuring blood glucose of more than $16.7 \mathrm{nM}$ for 3 successive days, we observed the animal models for an additional 4 weeks. After body weights were measured, urinary albumin, urinary protein, SOD activity and malondialdehyde (MDA) were measured by ELISA, BCA and biochemical assay respectively. Moreover, plasma insulin was assayed by radioimmunoassay, insulin expression in pancreatic $\beta$ cells was assayed by immunohistochemistry and receptor for advanced glycation end products (RAGE) and corresponding PKC and PKA signaling in the kidney cortex were also assayed by Western blot and Real-time PCR. Results: The results showed that Apn can significantly reduce MDA and enhance SOD activity. Moreover, Apn promoted the synthesis and secretion of insulin by islet $\beta$-cells and reduced RAGE accumulation in the kidney, which was associated with down-regulated PKC expression and upregulated PKA expression. Conclusion: Apn has protective effects against hyperglycemia and can effectively enhance antioxidation, promote the secretion of insulin and reduce the accumulation of glycosylated products in T2DM mice; these effects were associated with inhibition of PKC and promotion of PKA signaling.




\section{Cellular Physiology Cell Physiol Biochem 2017;43:870-878

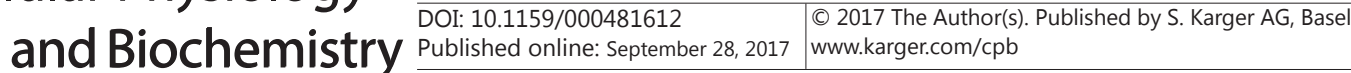 \\ Hu et al.: Adiponectin Protects Against Diabetic Kidney Injury}

\section{Introduction}

Diabetes mellitus (DM) was one of the first diseases to be documented, having been recorded in an Egyptian manuscript 3000 years ago. It is a chronic lifelong disease characterized by hyperglycemia resulting from defects in insulin secretion, insulin action, or both [1]. DM is divided into type 1 and type 2 DM (T2DM). T2DM, which occurs mostly in middle-aged and elderly persons, is the most common form of diabetes and is characterized by disorders of insulin action and insulin secretion, either of which may be the predominant feature [2]. The specific reasons for the development of these abnormalities are not yet known. However, it may be associated with genetic factors, endocrine dysfunction, metabolic disturbance, immune function disorder, microbial infection, toxins, mental factors, or other risks $[3,4]$. Diabetic kidney injury is a severe complication induced by DM, involving injuries to various cell types in the kidney [5,6]. Recent evidence shows that glucose-dependent advanced glycation end products (AGEs) play key roles in the pathogenesis of renal injury [7]. Increased accumulation of AGEs promotes protein kinase $C$ (PKC), suppresses protein kinase A (PKA) and activates the oxidative stress response [8]. PKC inhibitors or PKA agonists may alleviate the injury by inhibiting enhanced oxidative responses [9].

Adiponectin (Apn), an endogenous biologically active polypeptide or protein secreted by adipocytes, is an insulin-sensitizing hormone and improves insulin resistance in mice, as well as arteriosclerosis [10]. In human studies, expression levels of Apn were able to predict T2DM and coronary heart disease, and in clinical trials Apn showed anti-diabetes, antiatherosclerosis and anti-cancer potential [11-13]. The Apn gene, located at 3p27, encodes a special collagenous protein consisting of 244 amino acids. It exists as oligomers including trimers (low molecular weight - LMW), hexamers (medium molecular weight - MMW) and a 42-kDa high-molecular-weight (HMW) complex, and the activity of HMW Apn is stronger than that of the LMW and MMW forms [14]. Kondo et al. identified a predisposing site for T2DM and metabolic syndrome at the locus of the Apn gene through extensive genome scans. They analyzed mutations in the Apn gene and identified four missense mutations in the globular region of the Apn gene, which were significantly more frequent in patients with T2DM than in controls. Moreover, the plasma Apn concentration decreased if mutations occurred, and all the mutations were associated with characteristics of metabolic syndrome, including hypertension, hyperlipidemia, diabetes and arteriosclerosis [15]. Further, Weyer verified that obesity and T2DM were associated with low plasma Apn concentrations in different ethnic populations, suggesting that Apn has a certain amount of value in the treatment of insulin resistance-related metabolic syndrome and T2DM [16]. In vitro experiments have shown that physiological concentrations (15 $25 \mathrm{mg} / \mathrm{L}$ ) of Apn can inhibit the expression of vascular cell adhesion molecule 1 (VCAM-1), E-selectin, intercellular adhesion molecule 1 (ICAM-1) induced by tumor necrosis factor $\alpha(\mathrm{TNF} \alpha)$ in a dose-dependent manner [17]. In cultured smooth muscle cells, Apn can reduce DNA synthesis induced by platelet-derived growth factor (PDGF), heparin-binding epidermal growth factor-like growth factor (HBEGF), basic fibroblast growth factor (bFGF), epidermal growth factor (EGF), thus reducing cell proliferation and migration [18]. In cultured endothelial cells, Apn reduces HB-EGF mRNA expression induced by TNF $\alpha$ [19]. These results suggest that Apn may have protective effects against T2DM-related kidney injury.

To understand the effects of Apn on diabetic kidney injury, we assessed the protective effects of glycosylated Apn on diabetes-related renal injury from sugar metabolism, oxidative stress, insulin secretion, AGE accumulation, and corresponding signaling.

\section{Materials and Methods}

Animals and treatment

The study protocol was approved by the Animal Ethics Committee of Renmin Hospital of Wuhan University. Eight-week-old female Wister mice were obtained from the experimental animal center of Wuhan 


\section{Cellular Physiology Cell Physiol Biochem 2017;43:870-878 \begin{tabular}{l|l|l} 
and BOI: 10.1159/000481612 & $\begin{array}{l}\text { C } 2017 \text { The Author(s). Published by S. Karger AG, Basel } \\
\text { www.karger.com/cpb }\end{array}$
\end{tabular}}

Hu et al.: Adiponectin Protects Against Diabetic Kidney Injury

University. All mice were specific pathogen free and weighed 20-22 g. After 1 week of adaptive feeding, 30 mice were randomly divided into a control group, a model group and three Apn groups and were marked and weighed. Globular Apn (low, $10 \mathrm{mg} / \mathrm{kg}$; medium, $25 \mathrm{mg} / \mathrm{kg}$; or high concentration, $100 \mathrm{mg} / \mathrm{kg}$ ) was purchased from Prospect Israel (Cat. number: CYT-432) and administered intravenously. Diabetic models were developed by feeding the mice a pro-diabetic high-fat diet for 4 weeks, while the normal control group continued to receive a regular diet. The pro-diabetic high-fat diet consisted of $86.8 \%$ standard laboratory chow, $3 \%$ cholesterol, $0.2 \%$ propyl thiouracil, and $10 \%$ lard. Following 4 weeks of dietary intervention, the model group and Apn groups were injected intraperitoneally with a high dose of STZ (Sigma-Aldrich, Darmstadt, Germany; $85 \mathrm{mg} / \mathrm{kg}$, dissolved in $0.1 \mathrm{M}$ sodium citrate buffer, $\mathrm{pH} 4.5$ ), while the normal control mice were injected with sodium citrate buffer at $1 \mathrm{ml} / \mathrm{kg}$. After 3 days of injection, fasting blood glucose was measured daily to verify the successful generation of the diabetic model. The model was considered successful when blood glucose increased to more than $16.7 \mathrm{nM}$ for 3 successive days. Urine was collected for 24 hours for testing. Urinary albumin was measured by ELISA (Cat. Number: M-02404, my biotechnology, Shanghai, China), and urinary protein by a BCA assay (Beyotime, Shanghai, China). Renal injury was considered verified when urinary protein increased more than 3-fold and urinary albumin increased by 50 -fold compared with the control. Then, the diabetic animals were fed with a regular diet for 4 consecutive weeks.

Measurement of fasting blood glucose and plasma insulin; collection of blood and tissue samples

All mice were weighed once a week, starting before treatment and continuing throughout the experimental period. Fasting blood glucose was measured with an OneTouch automatic glucose analyzer between 8:30 am and 9:30 am using from the tail vein. For additional biochemical analysis, blood was extracted from the eyes and then centrifuged $\left(3500 \mathrm{rpm}\right.$ at $4^{\circ} \mathrm{C}$ for $\left.10 \mathrm{~min}\right)$ to obtain serum. A 1:10 dilution of serum was assayed for insulin content using a radioimmunoassay (RIA) kit (Millipore, Shanghai, China) following the manufacturer's instructions. The serum SOD and MDA levels were examined with an ultraviolet spectrophotometer. The mice were dissected, and the kidneys were removed and homogenized. SOD activity and MDA content were measured in the kidney homogenate.

The expression of insulin in mouse pancreatic $\beta$ cells

Islets from the mice were placed in $10 \%$ formalin solution for $48 \mathrm{~h}$, then embedded in paraffin and sectioned. The expression of insulin was detected by immunohistochemical staining with a rabbit antimouse insulin antibody (Cat. number: ab63820; Abcam, MA, USA) and HRP-conjugated goat anti-rabbit IgG (Boster, Wuhan, China).

\section{Western blot}

Total protein was extracted from the kidney cortex by lysing the cells in RIPA buffer on ice for 30 min (Dingguo, Beijing, China), and equal amounts (50 $\mu \mathrm{g}$ ) of total protein were separated by $12 \%$ SDS-PAGE and transferred onto a PVDF membrane (Dingguo, Beijing, China). The PVDF membrane was blocked with $5 \%$ skim milk containing $0.1 \%$ TWEEN 20 and incubated with rabbit polyclonal antibodies against RAGE (Cat. number: ab30381; Abcam, MA, USA), anti-PKCßII (Cat. number: ab32026; Abcam, MA, USA), anti-PKA (Cat. number: ab75991; Abcam, MA, USA) and anti- $\beta$-actin (Cat. number: ab8227; Abcam, MA, USA). Then, HRP-conjugated secondary antibody was added and enhanced chemiluminescence (ECL) reagent (Dingguo, Beijing, China) was used for detection.

\section{Real-time polymerase chain reaction}

Total RNA from isolated kidney cortex was extracted with RNeasy Mini Kits (Qiagen, Shanghai, China). Then, $2 \mu \mathrm{g}$ of total RNA was used to synthesize first-strand cDNA with AMV reverse transcriptase (Thermo Fisher Scientific Co., Shanghai, China). Real-time fluorescent quantitative PCR was performed with a SYBR Green PCR kit (Thermo Fisher Scientific Co., Shanghai, China) on an Applied Biosystems 7300 Real-Time PCR System (Life Technologies Corporation, CA, USA). The following primers were used in the study: 5'-CCCTCGCCTGTTAGTTGC-3' and 5'-CTGGGTGCTGGTTCTTGC-3' (RAGE); 5'-ACGAGAAGCCAGCAAACT-3' and 5'-AAGCGAGACACCTCCAAC-3' (PKC 3 ); 5'-GAAAGACCTCACGCAGTT-3' and 5'-GGGAGGAGAAAGATAGCC-3' (PKA). In addition, $\beta$-actin was used as an internal control for normalizing mRNA expression [20]. 


\section{Statistical analysis}

Experimental data was analyzed with the SPSS 17.0 package. The results were presented as the mean \pm standard deviation (SD). We performed one-factor analysis of variance. The differences between the control group and each experimental group were assessed by $t$-test. A probability level of less than 0.05 or 0.01 was considered significant.

\section{Results}

Effect of Apn on the sugar metabolism and kidney function of T2DM mice

The body weights of experimental mice each week after the successful generation of the diabetes model are listed in Fig. 1A, and there were no significant differences in body weight among groups at any of the measured time points. Fig. $1 \mathrm{~B}$ shows the fasting blood glucose levels of the T2DM mice. Compared with the control group, the model group had higher fasting blood glucose levels throughout the experiment $(\mathrm{P}<0.01)$. Compared with the model group, fasting blood glucose levels in the Apn (L) group were significantly reduced starting at the end of the third week, and those in the Apn (M) and Apn (H) groups were obviously reduced starting at the end of the first week $(\mathrm{P}<0.01)$, indicating that Apn has a hypoglycemic effect. Fig. 1C shows that the urinary albumin of the mice in the model group

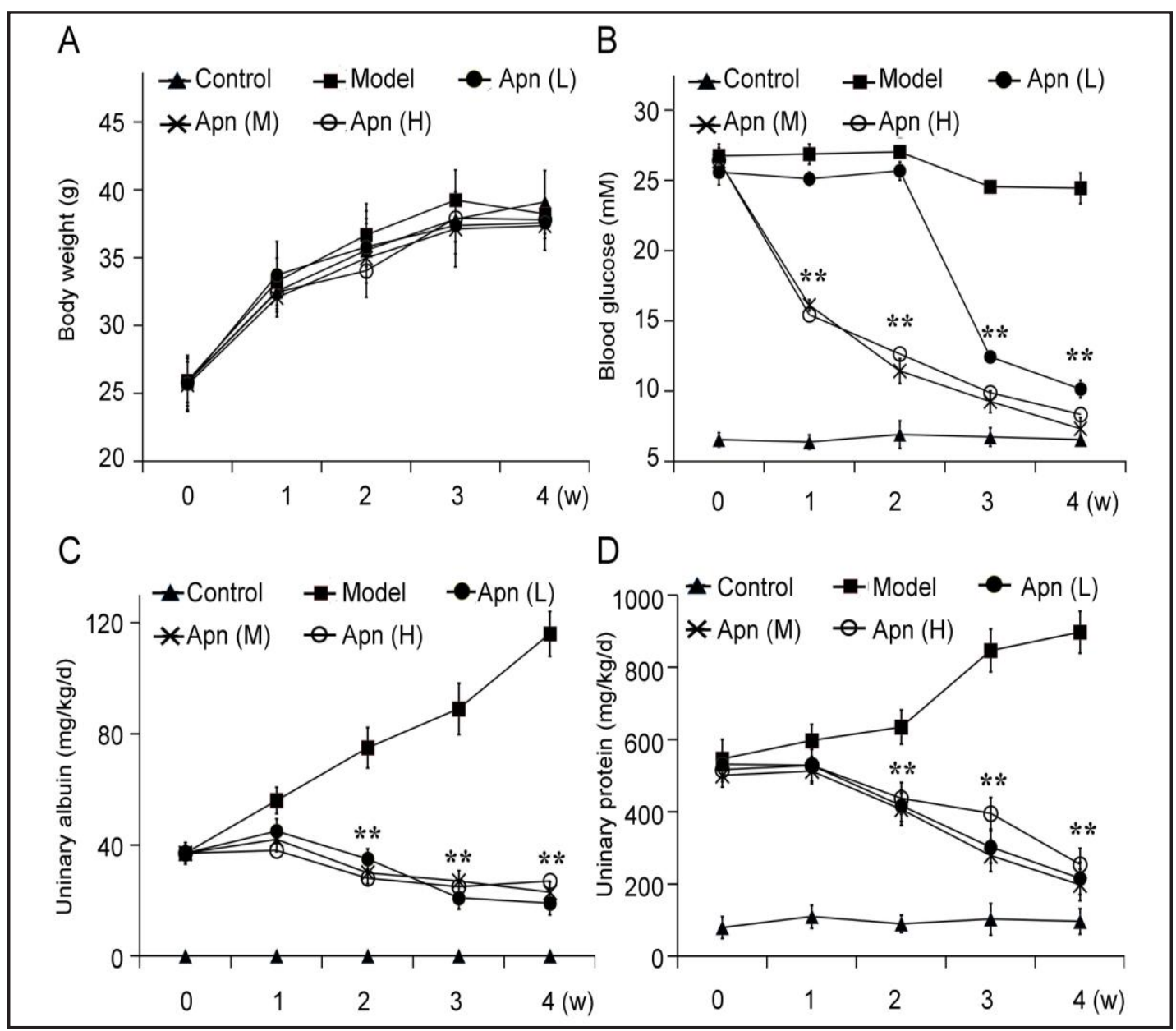

Fig. 1. Body weight, blood glucose, urinary albumin and urinary protein were examined at different time points after successful generation of a diabetic model $(n=6)$. A: Protective effects of Apn on body weight in T2D mice. B: Effects of Apn on blood glucose in T2D mice. C: Effects of Apn on urinary albumin levels in T2D mice. D: Effects of Apn on urinary protein levels in T2D mice. ${ }^{*} \mathrm{P}<0.01$, Apn group versus model group. 


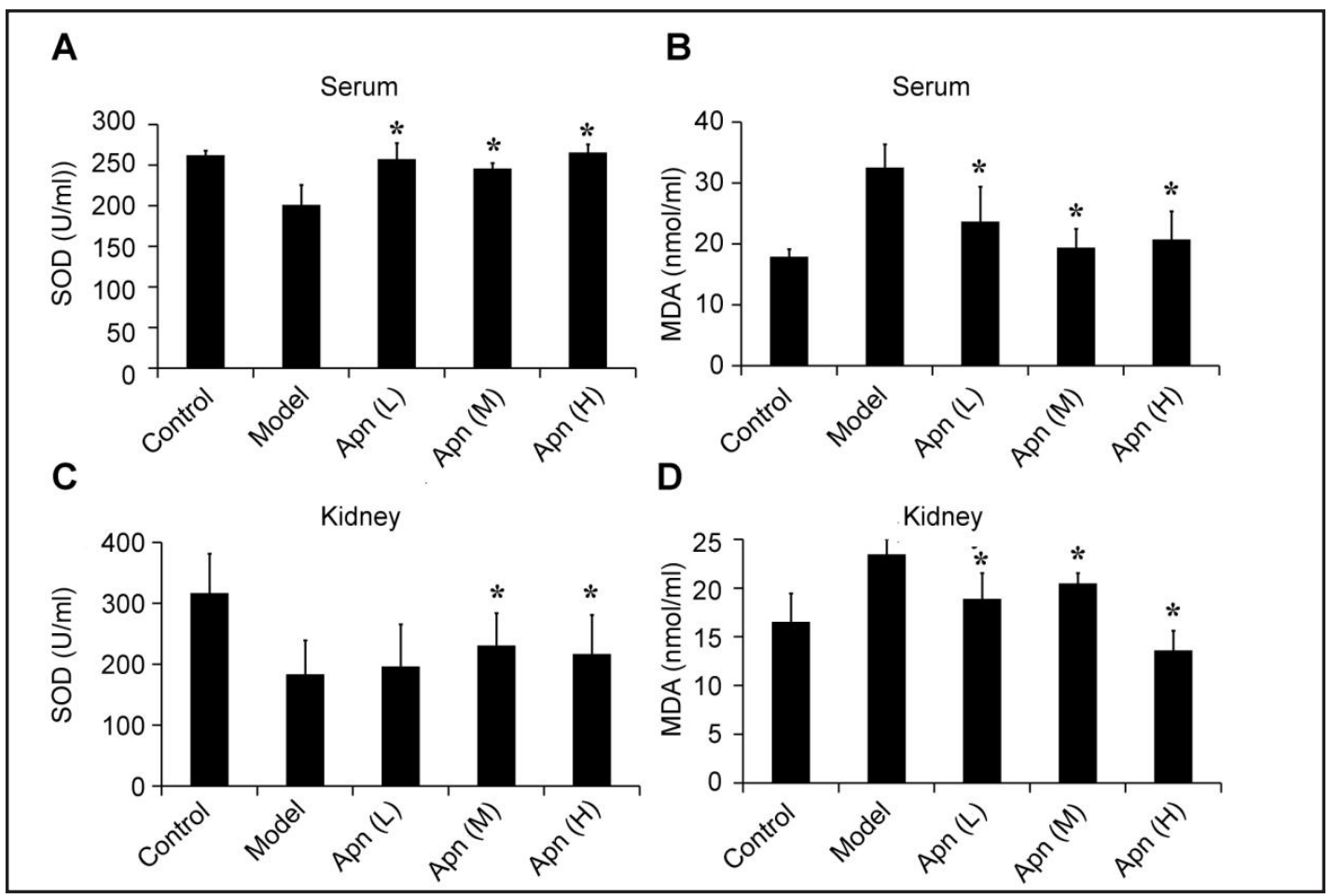

Fig. 2. SOD and MDA in serum and kidney cortex were examined at the end of week $4(n=6) .{ }^{*} P<0.05$, Apn group versus model group.

was significantly higher than that of the mice in the control group $(\mathrm{P}<0.01)$, while the Apn groups showed significantly lower urinary albumin than the model group starting the end of the second week $(\mathrm{P}<0.01)$. Fig. 1D shows that the urinary protein level of the mice in the model group was significantly higher than that of the mice in the control group $(\mathrm{P}<0.01)$, while the Apn groups showed significantly decreased urinary protein compared with the model group $(\mathrm{P}<0.01)$ from the end of the second week onward.

\section{Effects of Apn on the antioxidant activities of T2DM mice}

Figures $2 \mathrm{~A}$ and B show that at the end of the experiment, serum SOD and kidney homogenate SOD were lower in the model group than in the control group $(\mathrm{P}<0.05)$ and that serum MDA and kidney homogenate MDA were higher in the model group than in the control group, while the Apn groups showed significantly increased serum and kidney homogenate SOD and decreased serum and kidney homogenate MDA compared with the model group (P $<0.05$ ), indicating that Apn had antioxidant activity in T2DM mice.

\section{Effects of Apn on the insulin secretion of T2DM mice}

Fig. 3 A shows insulin secretion from the pancreas. The results showed that the diabetic model group had fewer islet $\beta$-cells than the control group and those $\beta$-cells synthesized and secreted less insulin. Apn increased the number of islet $\beta$-cells and the synthesis and secretion of insulin, indicating that Apn can significantly increase resistance to pancreatic $\beta$-cell injury and apoptosis in T2DM and promote the recovery, development and growth of those cells. Fig. 3 B shows the insulin content of plasma. The results also showed that Apn elevated the synthesis and secretion of insulin compared with the model group.

\section{Effects of Apn on RAGE, PKC and PKA expression}

Hyperglycemia leads to the activation of RAGE, triggers PKC signaling, and inhibits PKA signaling. The Western blot results (Fig. 4A) showed that, compared with normal controls, 


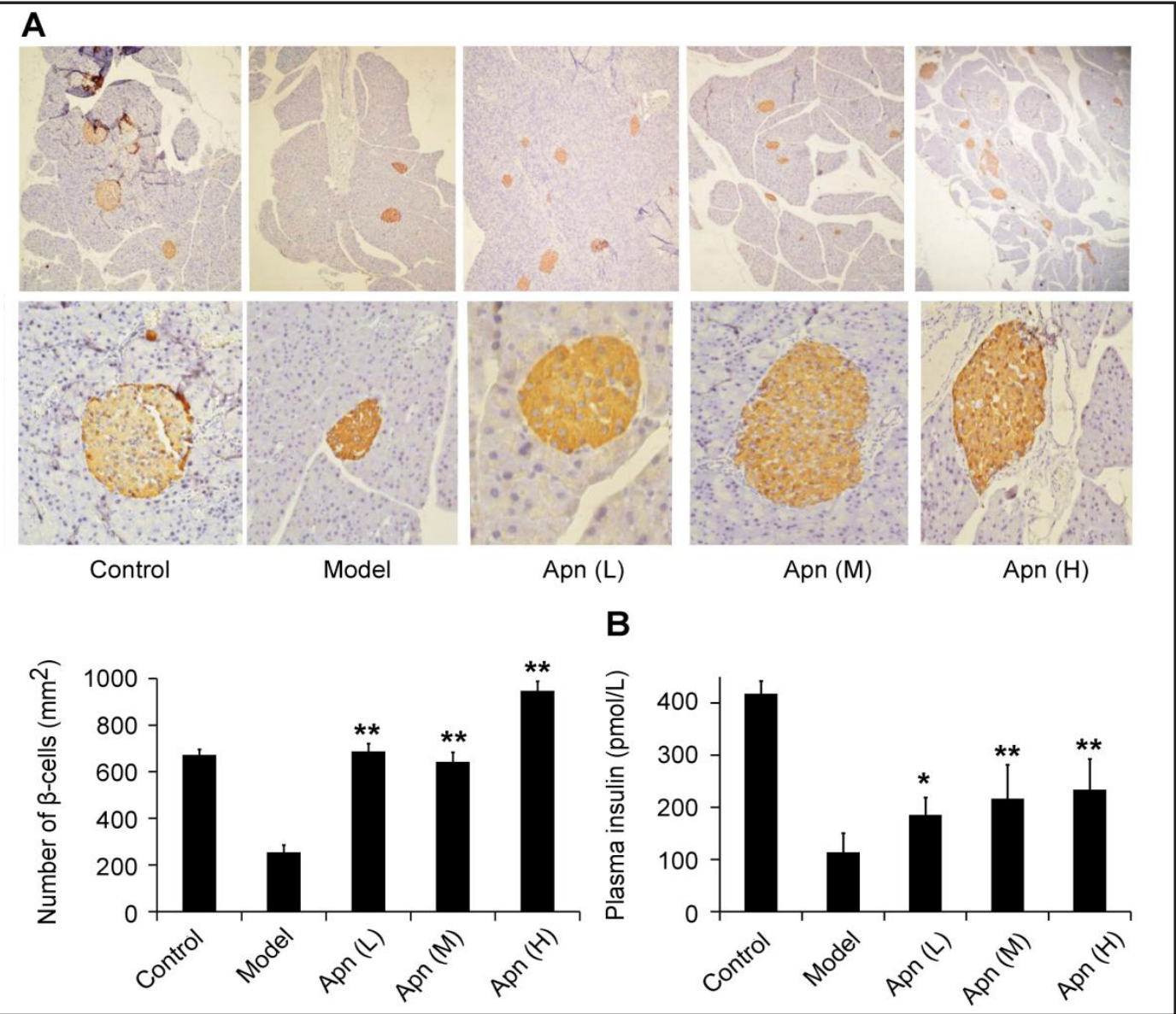

Fig. 3. Effects of Apn on insulin secretion (n=6). A: Insulin secretion from islet $\beta$-cells. Upper panel, $100 \mathrm{x}$ magnifications; lower panel, $400 \mathrm{x}$ magnifications. B: Insulin concentration in the plasma. $* \mathrm{P}<0.05$ and ** $\mathrm{P}<0.01$, Apn group versus model group.

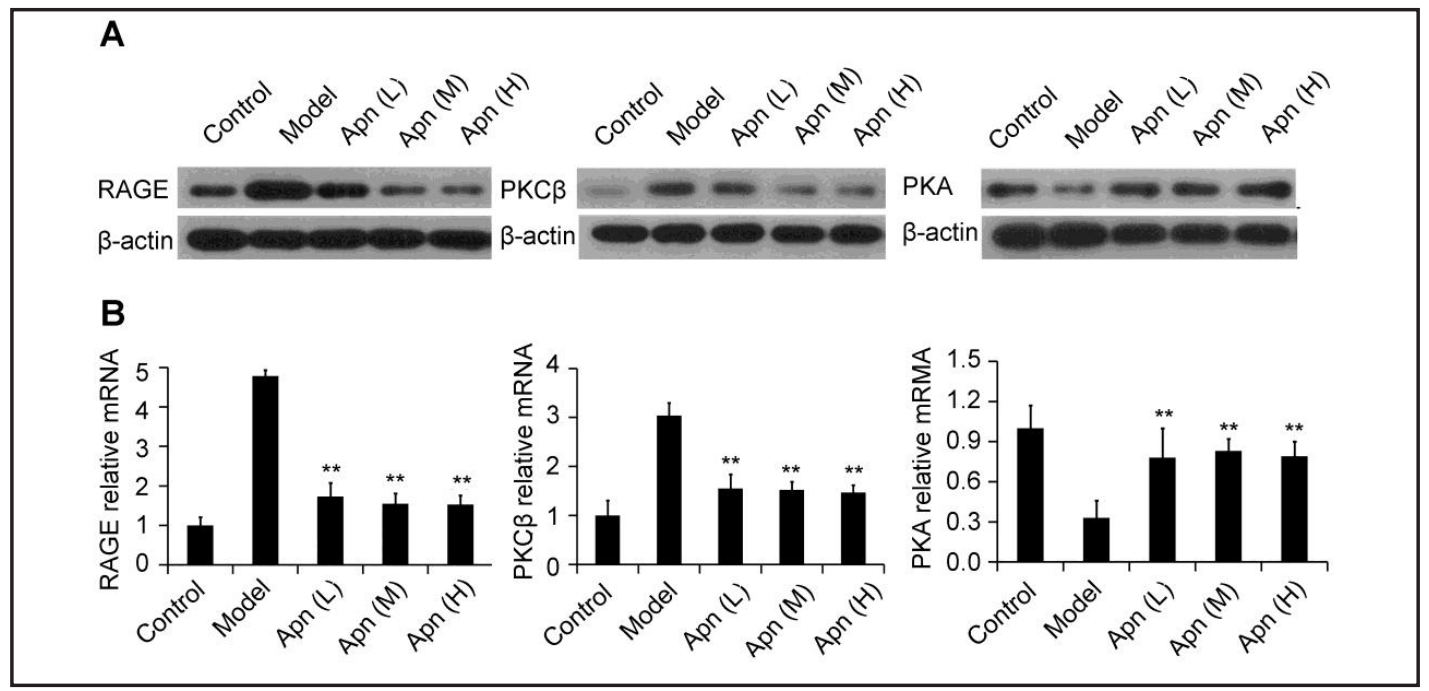

Fig. 4. Effects of Apn on RAGE, PKC $\beta$ and PKA expression in kidney cortex. Western blotting (A) and realtime PCR (B, n=6) were used to evaluate the expression levels of RAGE, PKC $\beta$ and PKA in glomerular tissues. ${ }^{* *} \mathrm{P}<0.01$, Apn group versus model group.

\section{KARGER}




\section{Cellular Physiology Cell Physiol Biochem 2017;43:870-878 \begin{tabular}{ll|l} 
and Biochemistry & $\begin{array}{l}\text { DOI: 10.1159/000481612 } \\
\text { Published online: September 28, } 2017\end{array}$ & $\begin{array}{l}\text { O 2017 The Author(s). Published by S. Karger AG, Basel } \\
\text { www.karger.com/cpb }\end{array}$ \\
\cline { 2 - 3 }
\end{tabular} \\ Hu et al.: Adiponectin Protects Against Diabetic Kidney Injury}

glomerular RAGE and PKC expression in T2D mice was significantly increased, whereas PKA expression was significantly decreased. Apn reduced RAGE activation in the kidney, downregulated PKC expression, and upregulated PKA expression in T2D mice. Similar results were also found by real-time PCR (Fig. 4B).

\section{Discussion}

The term DM describes a metabolic disorder of multiple etiologies characterized by chronic hyperglycemia with disturbances of carbohydrate, fat and protein metabolism resulting from defects in insulin secretion, insulin action, or both. Sustained hyperglycemia produces pathologic consequences by injuring many important organs, including the kidneys. In this study, we investigated the protective effects of Apn against kidney injury in T2DM mice. The results showed that the blood glucose levels in the Apn group were significantly lower than those in the model group, indicating that Apn has an obvious preventive effect against T2DM induced by the combination of a high-fat diet and STZ. Urinary albumin and urinary protein were significantly reduced in the Apn group compared with model group, indicating that Apn had a significant effect on the prevention of renal injury.

Many reports have shown that glycosylation of protein groups increases in type 1 and type $2 \mathrm{DM}$. The first change is the nonenzymatic addition of glucose to protein amino groups to form Amadori products. Amadori products are formed with albumin, hemoglobin, and lipoproteins (LDL). Amadori products of LDL increase the production of reactive oxidative species (ROS) in diabetic patients. Some antioxidant enzymatic actions of albumin are reduced in diabetes patients [21], disrupting the dynamic balance between the production and clearance mechanisms of free radicals in the body. Oxidative stress damages the islet $\beta$-cells, leading to the apoptosis of those cells and thereby reducing the number of pancreatic $\beta$-cells [22]. At the same time, oxidative stress reduces the sensitivity of peripheral tissues to insulin and causes the body to develop insulin resistance. Antioxidants reduce the production of free radicals in the body or directly quench free radicals and enhance the body's antioxidant capacity. At present, there are many antioxidants that have been studied and applied in clinical practice, such as vitamin E, vitamin C, GSH and alpha-lipoic acid (LA), which interact with a network of antioxidant, regenerative, and recycling processes. In the present study, serum SOD and kidney homogenate slurry SOD activity levels were significantly increased, while serum MDA and kidney homogenate slurry MDA were significantly decreased in all three Apn groups, indicating that Apn can effectively prevent excessive oxidative stress in T2DM mice and enhance their antioxidant capacity compared with that of the model group. Apn also significantly decreased pancreatic $\beta$-cell injury and apoptosis and promoted their recovery, development and growth, which led to increase insulin secretion. These results showed that Apn gave T2DM mice a certain degree of increased resistance to excessive oxidative stress induced by a high-fat diet and STZ and enhanced their antioxidant capacity.

Oxidative stress significantly increases the levels of advanced glycosylation end products (AGEs), which interact with their receptor RAGE to promote the pathogenesis of renal injury by activating some signaling molecules such as MAPK, NF- $\kappa B$ and PKC $[23,24]$. The PKC- $\beta$ isoforms are major players in the pathological changes involved in the renal injury that accompanies DM [25]. Moreover, activation of RAGE leads to up-regulation of PKC- $\beta$ and down-regulation PKA, thereby promoting renal injury [26, 27] (Fig. 5). In this study, Apn reduced renal injury by inhibiting RACE and PKC and promoting PKC signaling.

In conclusion, Apn has protective effects against renal injury and can effectively enhance the antioxidant capacity and insulin secretion of T2DM mice by promoting PKC signaling and inhibiting PKA signaling. 


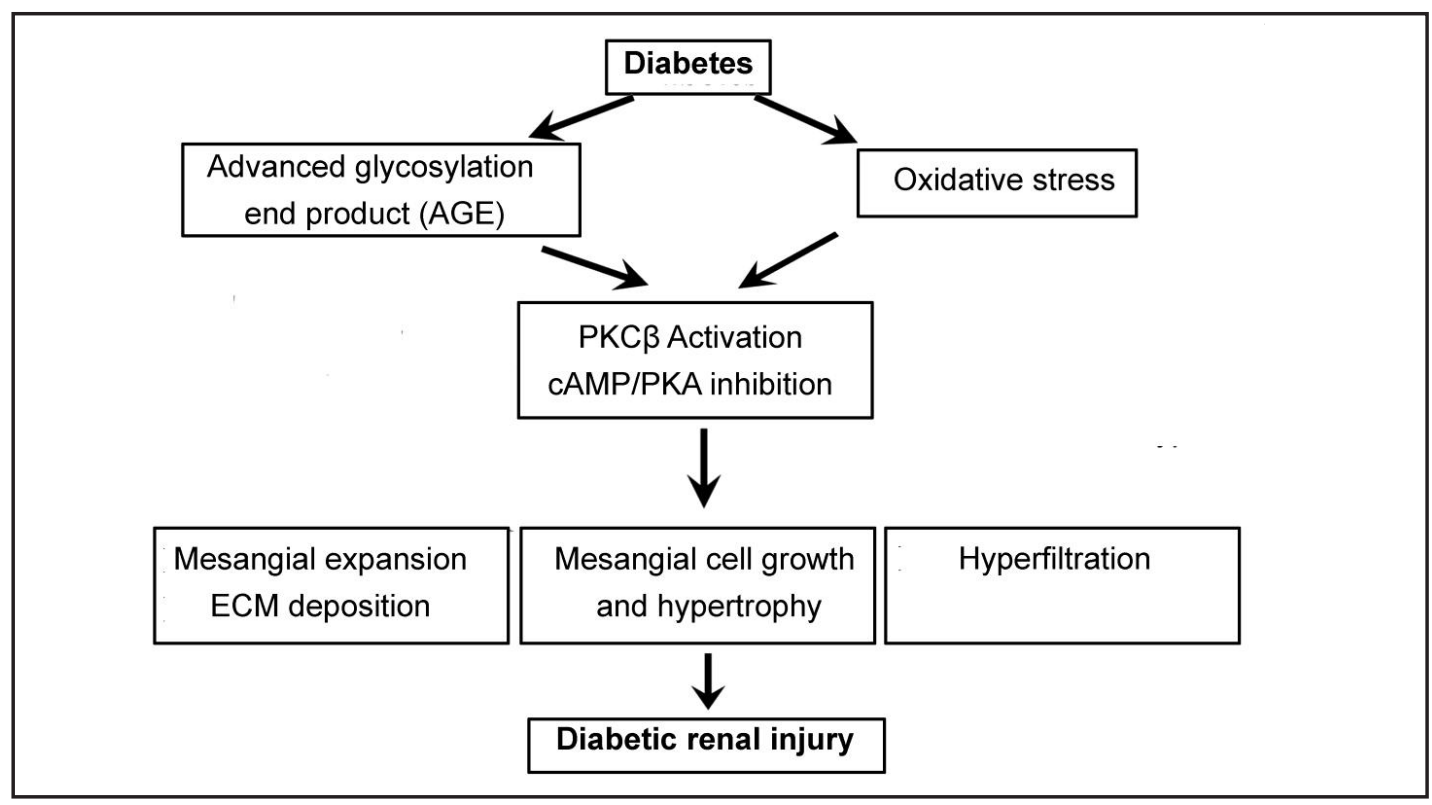

Fig. 5. Mechanism of development of diabetic renal injury. Glycosylation of protein groups (yielding AGEs) and oxidative stress induced by diabetes lead to up-regulation of PKC- $\beta$ and down-regulation PKA, thereby promoting diabetic renal injury.

\section{Abbreviations}

Apn (adiponectin); RAGE (receptor for advanced glycation end products); DM (diabetes mellitus); T2DM (type 2 DM); PKC (protein kinase C); PKA (protein kinase A); PDGF (plateletderived growth factor); HB-EGF (heparin-binding epidermal growth factor-like growth factor); bFGF (basic fibroblast growth factor); EGF (epidermal growth factor).

\section{Disclosure Statement}

The authors declare that no competing interests exist.

\section{References}

1 Saxena A, Sachin K, Bhatia AK: System Level Meta-analysis of Microarray Datasets for Elucidation of Diabetes Mellitus Pathobiology. Curr Genomics 2017;18:298-304.

$>2$ Armato J, Ruby R, Reaven G: Plasma triglyceride determination can identify increased risk of statininduced type 2 diabetes: a hypothesis. Atherosclerosis 2015;239:401-404.

-3 Dooley J, Tian L, Schonefeldt S, Delghingaro-Augusto V, Garcia-Perez JE, Pasciuto E, Di Marino D, Carr EJ, Oskolkov N, Lyssenko V, Franckaert D, Lagou V, Overbergh L, Vandenbussche J, Allemeersch J, Chabot-Roy G, Dahlstrom JE, Laybutt DR, Petrovsky N, Socha L, Gevaert K, Jetten AM, Lambrechts D, Linterman MA, Goodnow CC, Nolan CJ, Lesage S, Schlenner SM, Liston A: Genetic predisposition for beta cell fragility underlies type 1 and type 2 diabetes. Nat Genet 2016;48:519-527.

4 Cani PD, Neyrinck AM, Fava F, Knauf C, Burcelin RG, Tuohy KM, Gibson GR, Delzenne NM: Selective increases of bifidobacteria in gut microflora improve high-fat-diet-induced diabetes in mice through a mechanism associated with endotoxaemia. Diabetologia 2007;50:2374-2383.

5 Nagasu H, Satoh M, Kiyokage E, Kidokoro K, Toida K, Channon KM, Kanwar YS, Sasaki T, Kashihara N: Activation of endothelial NAD(P)H oxidase accelerates early glomerular injury in diabetic mice. Lab Invest 2016;9:25-36.

6 Pedagogos E, Hewitson T, Fraser I, Nicholls K, Becker G: Myofibroblasts and arteriolar sclerosis in human diabetic nephropathy. Am J Kidney Dis 1997;29:912-918. 


\section{Cellular Physiology Cell Physiol Biochem 2017;43:870-878 \begin{tabular}{l|l|l} 
and Biochemistry $10.1159 / 000481612$ & (c) 2017 The Author(s). Published by S. Karger AG, Basel \\
www.karger.com/cpb
\end{tabular}

7 Sun H, Yuan Y, Sun Z: Update on Mechanisms of Renal Tubule Injury Caused by Advanced Glycation End Products. Biomed Res Int 2016;2016:5475120.

8 Jiang Y, Zhang W, Xu S, Lin H, Sui W, Liu H, Peng L, Fang Q, Chen L, Lou J: Transplantation of human fetal pancreatic progenitor cells ameliorates renal injury in streptozotocin-induced diabetic nephropathy. J Transl Med 2017;15:147.

-9 Das J: Novel N-pyrimidin-4-yl-3-amino-pyrrolo [3, 4-C] pyrazole derivatives as PKC kinase inhibitors: a patent evaluation of US2015099743 (A1). Expert Opin Ther Pat 2016;26:523-528.

10 Hossain MM, Mukheem A, Kamarul T: The prevention and treatment of hypoadiponectinemia-associated human diseases by up-regulation of plasma adiponectin. Life Sci 2015;135:55-67.

-11 El Husseny MW, Mamdouh M, Shaban S, Ibrahim Abushouk A, Zaki MM, Ahmed OM, Abdel-Daim MM: Adipokines: Potential Therapeutic Targets for Vascular Dysfunction in Type II Diabetes Mellitus and Obesity. J Diabetes Res 2017;2017:8095926.

12 Gao Q Yao X, Zheng J: MiR-323 Inhibits Prostate Cancer Vascularization Through Adiponectin Receptor. Cell Physiol Biochem 2015;36:1491-1498.

13 Zeng F, Shi J, Long Y, Tian H, Li X, Zhao AZ, Li RF, Chen T: Adiponectin and Endometrial Cancer: A Systematic Review and Meta-Analysis. Cell Physiol Biochem 2015;36:1670-1678.

14 Hampe L, Radjainia M, Xu C, Harris PW, Bashiri G, Goldstone DC, Brimble MA, Wang Y, Mitra AK: Regulation and Quality Control of Adiponectin Assembly by Endoplasmic Reticulum Chaperone ERp44 J Biol Chem 2015;290:18111-18123.

15 Kondo H, Shimomura I, Matsukawa Y, Kumada M, Takahashi M, Matsuda M, Ouchi N, Kihara S, Kawamoto T, Sumitsuji S, Funahashi T, Matsuzawa Y: Association of adiponectin mutation with type 2 diabetes: a candidate gene for the insulin resistance syndrome. Diabetes 2002;51:2325-2328.

16 Weyer C, Funahashi T, Tanaka S, Hotta K, Matsuzawa Y, Pratley RE, Tataranni PA: Hypoadiponectinemia in obesity and type 2 diabetes: close association with insulin resistance and hyperinsulinemia. J Clin Endocrinol Metab 2001;86:1930-1935.

17 Ouedraogo R, Gong Y, Berzins B, Wu X, Mahadev K, Hough K, Chan L, Goldstein BJ, Scalia R: Adiponectin deficiency increases leukocyte-endothelium interactions via upregulation of endothelial cell adhesion molecules in vivo. J Clin Invest 2007;117:1718-1726.

18 Wang Y, Lam KS, Xu JY, Lu G, Xu LY, Cooper GJ, Xu A: Adiponectin inhibits cell proliferation by interacting with several growth factors in an oligomerization-dependent manner. J Biol Chem 2005;280:18341-18347.

19 Khan S, Shukla S, Sinha S, Meeran SM: Role of adipokines and cytokines in obesity-associated breast cancer: therapeutic targets. Cytokine Growth Factor Rev 2013;24:503-513.

20 Wang L, Wu G, Qin X, Ma Q Zhou Y, Liu S, Tan Y: Expression of Nodal on Bronchial Epithelial Cells Influenced by Lung Microbes Through DNA Methylation Modulates the Differentiation of T-Helper Cells. Cell Physiol Biochem 2015;37:2012-2022.

21 Miranda-Díaz AG, Pazarín-Villaseñor L, Yanowsky-Escatell FG, Andrade-Sierra J: Oxidative Stress in Diabetic Nephropathy with Early Chronic Kidney Disease. J Diabetes Res 2016;2016:7047238.

-22 Swisa A, Glaser B, Dor Y: Metabolic Stress and Compromised Identity of Pancreatic Beta Cells. Front Genet 2017;8:21.

-23 Lu C, He JC, Cai W, Liu H, Zhu L, Vlassara H: Advanced glycation endproduct (AGE) receptor 1 is a negative regulator of the inflammatory response to AGE in mesangial cells. Proc Natl Acad Sci USA 2004;101:1176711772.

24 Singh J, Chaudhari BP, Kakkar P: Baicalin and chrysin mixture imparts cyto-protection against methylglyoxal induced cytotoxicity and diabetic tubular injury by modulating RAGE, oxidative stress and inflammation. Environ Toxicol Pharmacol 2017;50:67-75.

25 Bhattacharya S, Manna P, Gachhui R, Sil PC: D-saccharic acid 1, 4-lactone protects diabetic rat kidney by ameliorating hyperglycemia-mediated oxidative stress and renal inflammatory cytokines via NF- $\kappa \mathrm{B}$ and PKC signaling. Toxicol Appl Pharmacol 2013;267:16-29.

-26 Qiu YY, Tang LQ, Wei W: Berberine exerts renoprotective effects by regulating the AGEs-RAGE signaling pathway in mesangial cells during diabetic nephropathy. Mol Cell Endocrinol 2017;443:89-105.

27 Xu S, Jiang Y, Wang H, Wang Z, Liu H, Peng L, Fang Q, Deng T, You J, Zhou X, Zhang W, Lou J: C-peptide ameliorates renal injury in type 2 diabetic rats through protein kinase A-mediated inhibition of fibronectin synthesis. Biochem Biophys Res Commun 2015;458:674-680. 